\title{
Compact Multibeam Array with Miniaturized Butler Matrix for 5G Applications
}

\author{
Suleiman A. Babale', Muhammad K. Ishfaq ${ }^{2, *}$, Ali Raza², Jamal Nasir ${ }^{3}$, Ahmad Fayyaz ${ }^{3}$ and \\ Umer Ijaz ${ }^{2}$
}

\author{
${ }^{1}$ Department of Electrical Engineering, Bayero University, Kano, Nigeria \\ ${ }^{2}$ Department of Electrical Engineering, Government College University Faisalabad, Pakistan \\ ${ }^{3}$ Department of Electrical and Computer Engineering, COMSATS University Islamabad, Abbottabad Campus, Pakistan \\ *Corresponding Author: Muhammad K. Ishfaq. Email: mkamranishfaq@gcuf.edu.pk \\ Received: 28 October 2021; Accepted: 21 December 2021
}

\begin{abstract}
This paper presents the design and implementation of a miniaturized beam steering network that produces broadside beams when it is fed with a compact antenna array. Butler Matrix (BM) was used as the beam steering network. It was completely built from a miniaturized $3 \mathrm{~dB}$ hybrid-couplers in planar microstrip technology. It was configured by feeding the BM with a Planar Inverted-E Antenna (PIEA) array separated at $0.3 \lambda$ as against the $0.5 \lambda$ separation. This makes the BM produce a major radiation pattern at the broadside. Apart from the miniaturization, no modification was made from the BM side. However, employing effective mutual coupling reduction techniques helped to design the compact PIEA array. The validity of this BM based multibeam PIEA array was demonstrated by comparing the simulation results of the reflection coefficients, transmissions coefficients and the radiation pattern with measurements. The measurement results showed good agreement with simulations.
\end{abstract}

Keywords: Beam steering; compact; butler matrix; grating lobe; and mutual coupling; PIEA array

\section{Introduction}

Beamforming arrays and multibeam antennas are key technology being employed in 5G to achieve high data rates. Multibeam antennas use beamforming networks (BFN) such as Rotman Lens and Butler Matrix (BM). Since the inception of the Butler matrix (BM) [1], researchers have put extensive effort into the realization of $\mathrm{BM}$ in a microstrip technique and other various technologies such as multi-layered [2], coplanar waveguide (CPW) [3], Swap port coupler [4], open-stubs [5], and substrate integrated waveguide (SIW) technology [6,7]. The design of Butler matrices in its classical form is based on transmission lines which are responsible for the bulky layout of the device. This is mostly due to the presence of fixed phase shifters, crossovers, and hybrid couplers employed in the design, with all their dimensions constrained by $\lambda / 4$ wavelength transmission lines (TL), which usually posed some

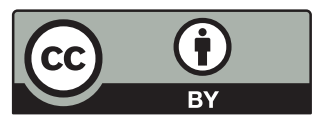

This work is licensed under a Creative Commons Attribution 4.0 International License, which permits unrestricted use, distribution, and reproduction in any medium, provided the original work is properly cited. 
challenges, most especially at lower frequencies [8]. This large circuit is needed to be reduced to have a compact system suitable for applications at all frequencies.

The microstrip technique is the simplest method of realizing BM as presented in [9]. Recently, size miniaturization of BM at lower frequencies, becomes an active research area. In [10], a transmission line was replaced with artificial transmission lines to design a compact BM. The multi-layered packaging technologies are another option for realising a miniaturized BM as presented in [11]. Further size reduction of the BM using the advanced complementary metal-oxide-semiconductor (CMOS) technology was reported in [12]. A high level of miniaturization of the BM was achieved. In [13], a lumped element was used to replace the $\lambda / 4$ wavelength TL of the phase shifters and the $3 d B$ hybrid couplers of the BM with the aim of reducing the size of BM. This technique drastically makes the BM compact in size.

Other researchers proposed a miniaturized BM by eliminating crossovers [14], elimination of phase shifters and crossovers [15]. In [16] coplanar-waveguide was reported, the coplanar-waveguide couplers utilize electromagnetic coupling via a slot in a common ground plane, therefore, the resulting circuit is without transmission line crossovers. A compact BM presented in [17] uses thin-film passive device technology. The complete BM was miniaturized by substituting the $\lambda / 4$ transmission line (TL) with a bridged-T coil. With this technique, the size of the BM produced was drastically reduced without sacrificing the performance of the BM significantly. Lumped-element equivalent of $\lambda / 4 \mathrm{TL}$ was applied in [4] using thin-film technology to produce a compact BM. Even though the circuit size reduces tremendously, but the bandwidth reduces proportionately because the conversion is usually applicable at a single frequency only. Another famous design problem of $\mathrm{BM}$ is that use of crossover points inevitable. To design a functional BM by avoiding crossing, a multi-layered technique is being used. This technique has the advantage of making the BM compact and at the same time eliminates the use of crossovers as proposed in [18].

The classical BM comprises of four hybrid couplers $(C 1-C 4)$, two-phase delays having $45^{\circ}$ phase shift and 2-crossovers as shown in Fig. 1. From this figure, the input ports are designated as $P 1-P 4$ where the $\mathrm{BM}$ is excited, $A 1-A 4$ are the outputs ports where antenna arrays are connected. These arrays radiate based on the choice of an appropriate input signal.

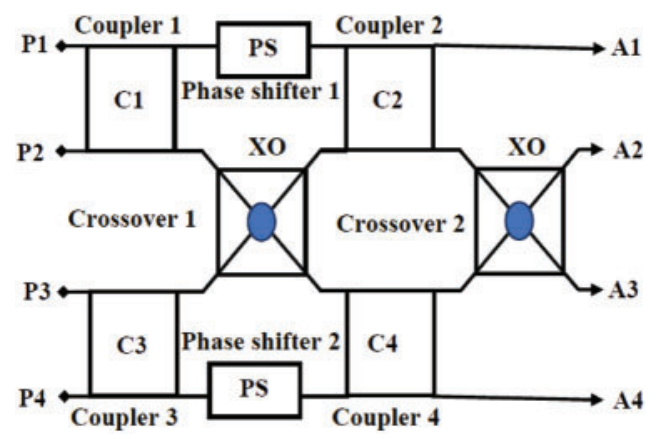

Figure 1: $4 \times 4$ Butler matrix block diagram

In this paper, the design and implementation of a beam steering network along with a compact PIEA array that produces a broadside beam are proposed at $6 \mathrm{GHz}$ for $5 \mathrm{G}$ applications. A miniaturized $\mathrm{BM}$ was implemented as the beam steering network that produces the broadside beam. This is contrary to the assertion made in [19] that it is not possible to use Butler matrices with $90^{\circ}$ hybrids couplers to 
produce a beam at broadside. The broadside beam is obtained by designing a compact PIEA array with $0.3 \lambda$ spacing, which utilises effective mutual coupling reduction techniques.

\section{Beam Steering Network}

Butler Matrix was used as the beam steering network. It was designed from a miniaturized coupler, phase shifters and cross-overs.

\subsection{Design of Miniaturized 3 dB Coupler}

The design equations of the $\lambda / 4$ wavelength transmission line (TL) and its T shaped equivalent circuit were accomplished using ABCD matrices as outlined in [20]. The size of a conventional coupler was drastically reduced by replacing it with an equivalent $\mathrm{T}$ section of the TL using the designed equations outlined in the same paper. In this design, care was taken to ensure that the impedance ratios were selected from the curve such that, the impedance of the original TL and that of the equivalent T-section are within the realizable boundary of microstrip technology. This is necessary because of fabrication issues, where very thin TL widths are difficult to be fabricated accurately.

The configuration of the coupler is shown in Fig. 2. P1 and P4 are the input and the isolation ports, whereas P2 and P3 serve as the output ports. All the lengths (L) represent the physical lengths of the sections as indicated in the Figure. To obtain the impedances of the coupler's such that their widths could be realised accurately, the curve in [20] was used. In this case, $M$ was chosen to be 1.7 which gives an impedance $Z_{1}=60 \Omega$, and with $K=2.6, Z_{2}=23.1 \Omega$ From the designed curve presented in [20], the impedances of the vertical arm of the coupler $(35 \Omega)$ was used to obtain the corresponding electrical length of that arm and are represented as: $Z_{1}=60 \Omega, Z_{2}=23.1 \Omega, Z_{3}=60 \Omega, \theta_{1}=17^{\circ}, \theta_{2}=39^{\circ}$, and $\theta_{3}=48^{\circ}$ respectively. Similarly, for the horizontal arm having an impedance of $Z_{0}=50 \Omega$, by selecting $K=3.3$ and $M=1.5$, the impedances are computed to be: $Z_{1}=75 \Omega, Z_{2}=22.7 \Omega, Z_{3}=75 \Omega$, and their electrical lengths are $\theta_{1}=16^{\circ}, \theta_{12}=31^{\circ}$, and $\theta_{3}=58^{\circ}$. Fig. 3 shows the layout and simulation results of the miniaturized coupler.

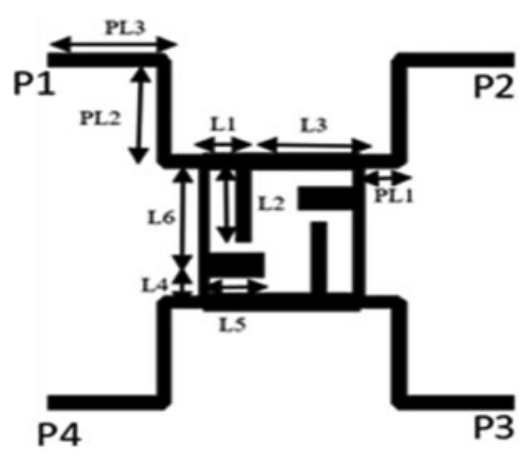

Figure 2: Schematic of the miniaturized coupler

These impedances and electrical lengths are used to obtain the physical lengths and widths of the coupler's lines and the stubs. The initial lengths and widths of the coupler have been optimized using a Genetic Algorithm (GA) embedded in the CST studio suit. The layout of the coupler is shown in Fig. 3a. The simulated S-parameter results showing the return loss and output phase difference are shown in Fig. $3 b$. 


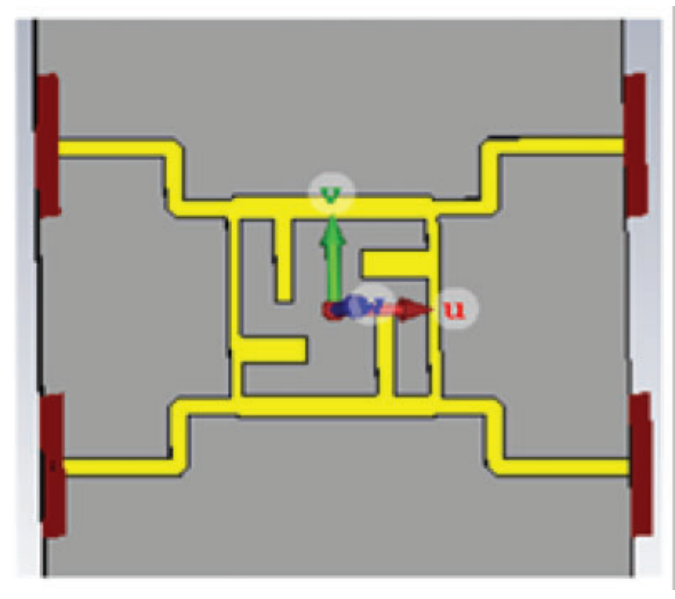

(a)

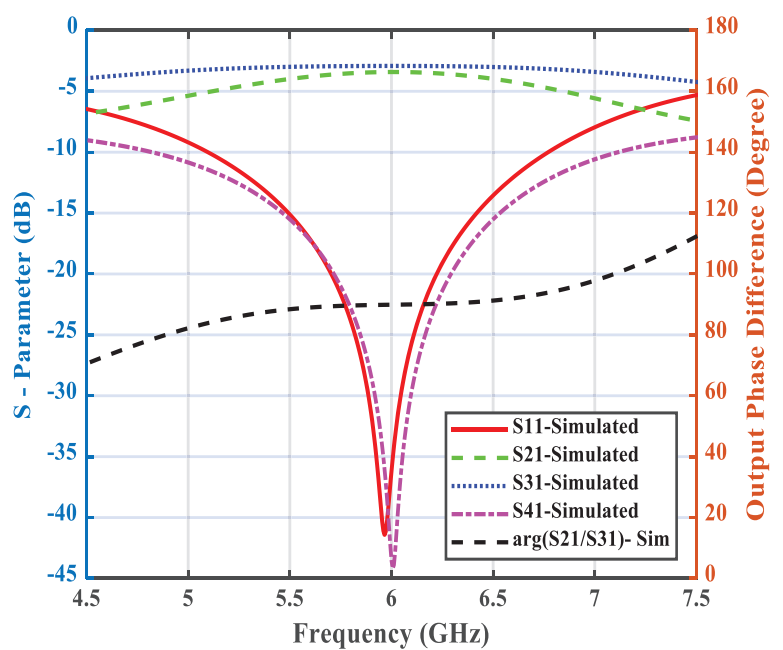

(b)

Figure 3: (a) Layout of the miniaturized coupler and (b) S-parameter results of the coupler

\subsection{Design of Miniaturized $3 \mathrm{~dB}$ Coupler}

This section explains the implementation of miniaturized crossover. It was implemented by cascading the two $90^{\circ}$ miniaturized couplers. But sometimes, the resulting structure has to be optimized to obtain better results. Fig. 4 shows the schematic of the miniaturized cross over. The crossover was designed such that, when the input port of P1 is excited with a signal ' $\mathrm{A}$ ', by applying standard hybrid analysis techniques, the signal emerges only at the diagonal port (P3) with, theoretically, no insertion loss. Practically, little power emerges from the remaining two ports P2 and P4.

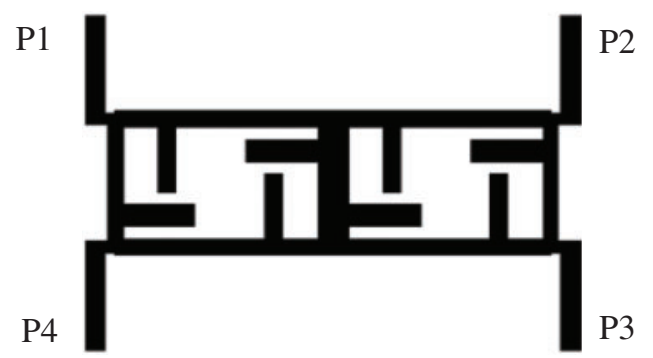

Figure 4: Layouts of the miniaturized crossover

The miniaturized $\mathrm{BM}$, crossover and phase shifters were used to form the proposed $\mathrm{BM}$ as explained in the next section.

\subsection{The Proposed Butler Matrix}

The miniaturized $3 \mathrm{~dB}$ coupler together with the crossovers designed in the previous section was used for the design of the miniaturized $4 \times 4 \mathrm{BM}$. The design was done in a modular manner where every component is treated independently. One of the couplers from the input side of the BM was first simulated alongside with the $45^{\circ}$ phase shifter and the crossover to obtain an output result usually multiple integral of $45^{\circ}$. Fig. 5 shows the circuit layout and the fabricated miniaturized BM without an antenna array. 


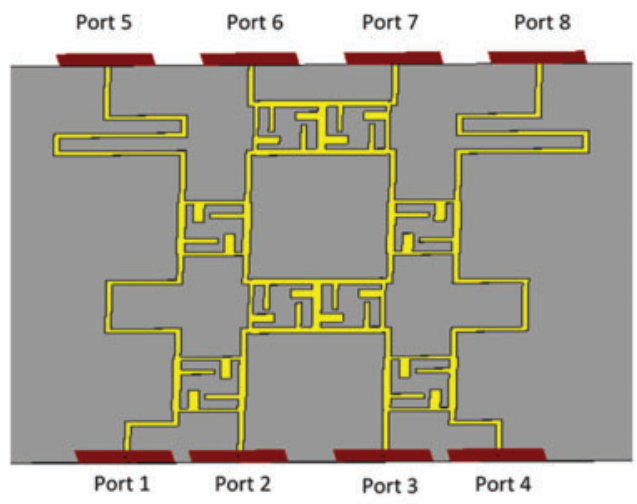

(a)

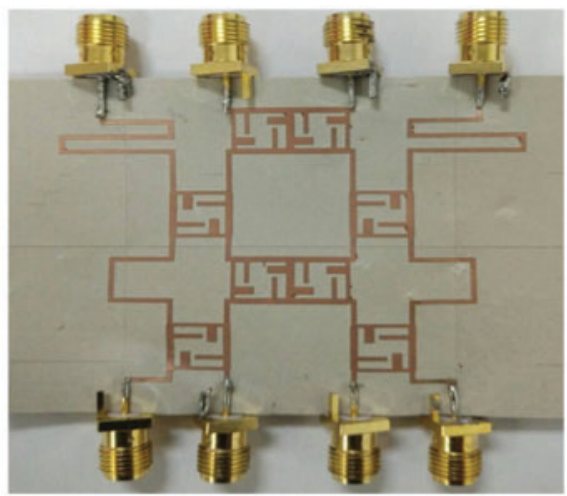

(b)

Figure 5: The miniaturized Butler matrix (a) The complete layout and (b) The photograph of the fabricated BM
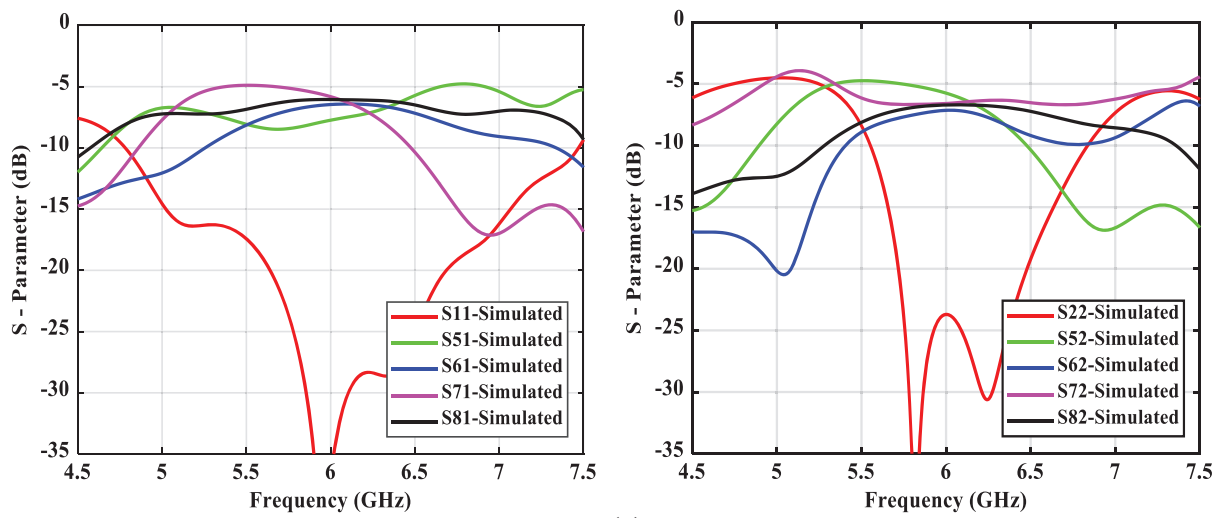

(a)
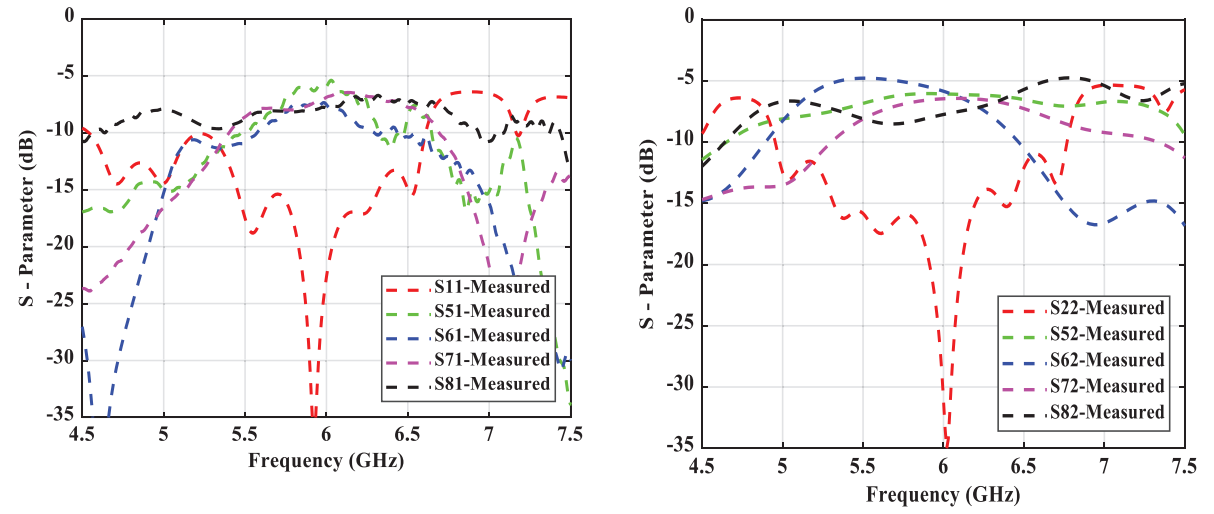

(b)

Figure 6: Simulated and measured the reflection and transmission coefficients when (a) Port 1 and (b) Port 2 are excited

Fig. 6a shows the scattering parameter results of the BM extracted from the full-wave simulator. The results presented are validated through measurement using a 4-port vector network analyser 
(VNA) and the performance characteristics obtained from the measured results of the BM by exciting all the ports separately are shown in Fig. 6b

The progressive phase differences of the miniaturized BM are plotted and shown in Fig. 7. From this figure, the differential output phases correspond to excitation of port 1 , are $-44.21^{0},-46.46^{0}$, and $-45.38^{\circ}$. When port 2 is excited, the progressive phase difference observed at the outputs are $+134.6^{0}$, $+135.90^{\circ}$, and $+136.85^{\circ}$. Due to the high symmetry of the device, the results obtained by exciting port 3 is the same as that of port 2 and the results of port 4 are the same as that of port 1 . The miniaturized $\mathrm{BM}$ was further tested by integrating an antenna array to obtain the radiation pattern.

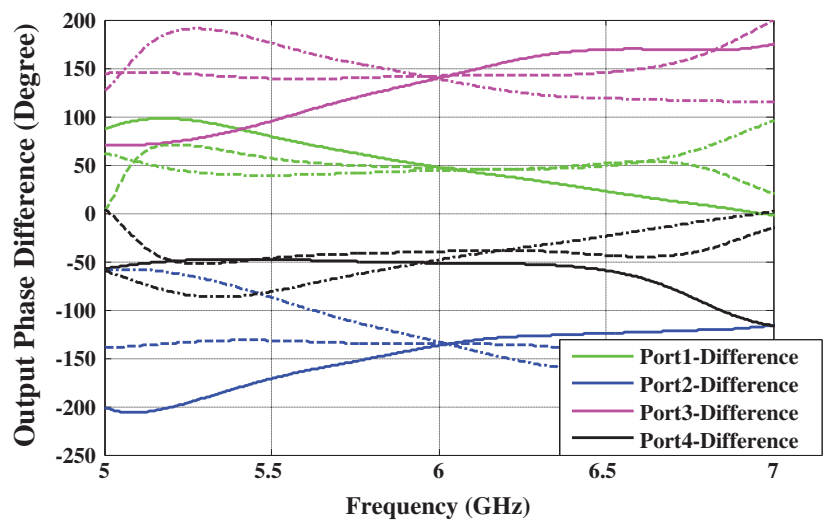

Figure 7: S-parameter results show the output phase differences when each port is excited separately

The performance of the proposed design has an average amplitude imbalance of $-6.87 \mathrm{~dB}$ at the centre frequency. Compared with other designs in Tab. 1, the miniaturized BM have better amplitude imbalance and average phase error at the centre frequency than others, it can further be observed that, in terms of the relative area, [7,13] are larger than the proposed BM while [10] has a smaller area with the poorest bandwidth.

Table 1: Performances of the proposed BM related to other Butler matrices

\begin{tabular}{llllll}
\hline Ref & Technique & $\begin{array}{l}\text { Average } \\
\text { amplitude } \\
\text { imbalance at } f_{0} \\
(\mathrm{~dB})\end{array}$ & $\begin{array}{l}\text { Average phase } \\
\text { error at } f_{0}(\mathrm{deg})\end{array}$ & Relative area & Band-width \\
& & -7.0 & $\pm 10^{0}$ & $3.5 \lambda_{0} \times 1.5 \lambda_{0}$ & $24 \%$ \\
\hline$[7]$ & SIW & -8.6 & $\pm 7^{0}$ & $0.33 \lambda_{0} \times 0.36 \lambda_{0}$ & $10.7 \%$ \\
{$[10]$} & Artificial TL & $\pm 20^{0}$ & $1.5 \lambda_{0} \times 1.5 \lambda_{0}$ & $8 \%$ \\
{$[13]$} & Lump elements & -7.9 & $\pm 7.46^{0}$ & $0.88 \lambda_{0} \times$ & $20.9 \%$ \\
Proposed BM & Microstrip & -6.87 & & $0.93 \lambda_{0}$ & \\
\hline
\end{tabular}

\section{Planar Inverted-E Antenna Array}

Firstly, a PIEA antenna was designed after an extensive parametric study and optimization. The top plate width, $\mathrm{W}$, the length $\mathrm{L}$, and the height $\mathrm{h}$, are optimized to obtain the desired resonance 
frequency. The feed width, $\mathrm{W}_{\mathrm{f}}$ is used to optimize enhanced bandwidth while the feed location $\mathrm{L}_{\mathrm{b}}$, is used to provide proper matching [21,22] at $6 \mathrm{GHz}$ for $5 \mathrm{G}[23,24]$. The air gap $\left(\varepsilon_{\mathrm{r}}=1\right)$ of $\mathrm{t}=0.5 \mathrm{~mm}$ between feed and ground. Figs. $8 \mathrm{a}$ and $8 \mathrm{~b}$ shows the geometry, radiation pattern and the return loss of the single element PIEA antenna. From this figure, it can be observed that a return loss better than $-27 d B$ was realized with an excellent radiation pattern having a gain of $4.35 d B i$, and $3 d B$ angular beam-width of 147.5 degrees.

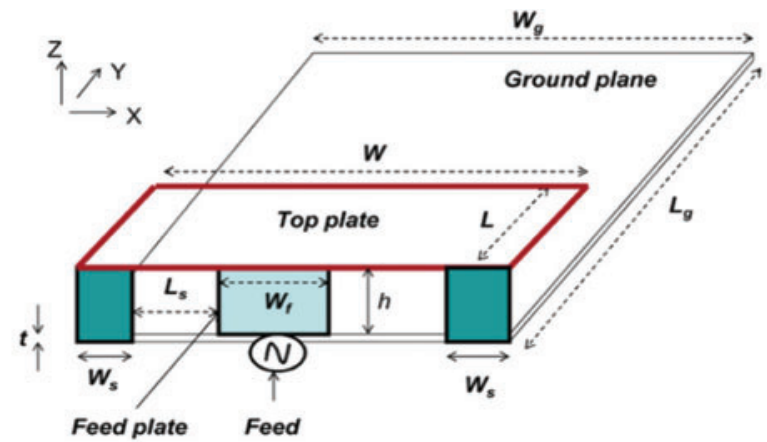

(a)
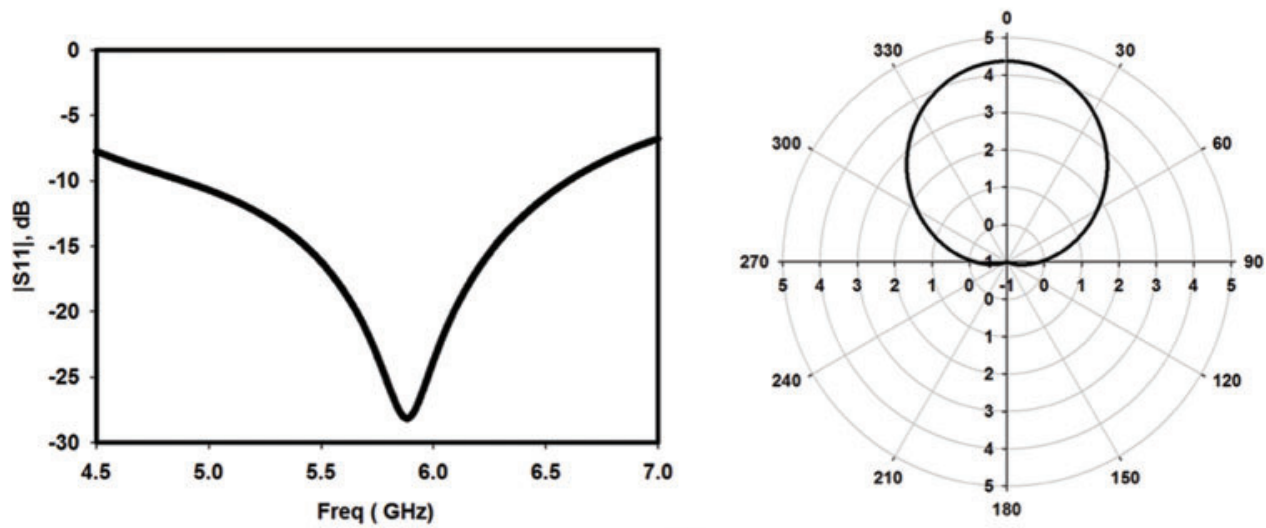

(b)

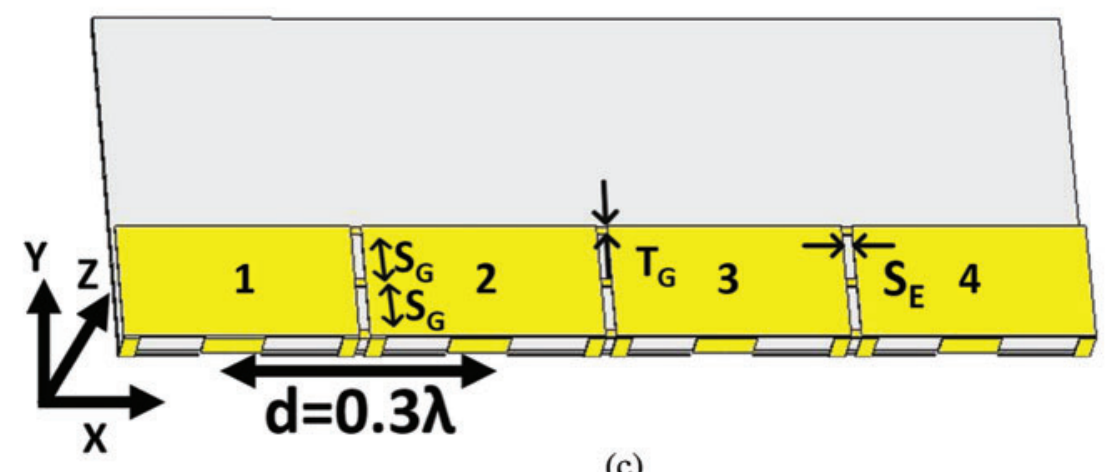

(c)

Figure 8: (Continued) 


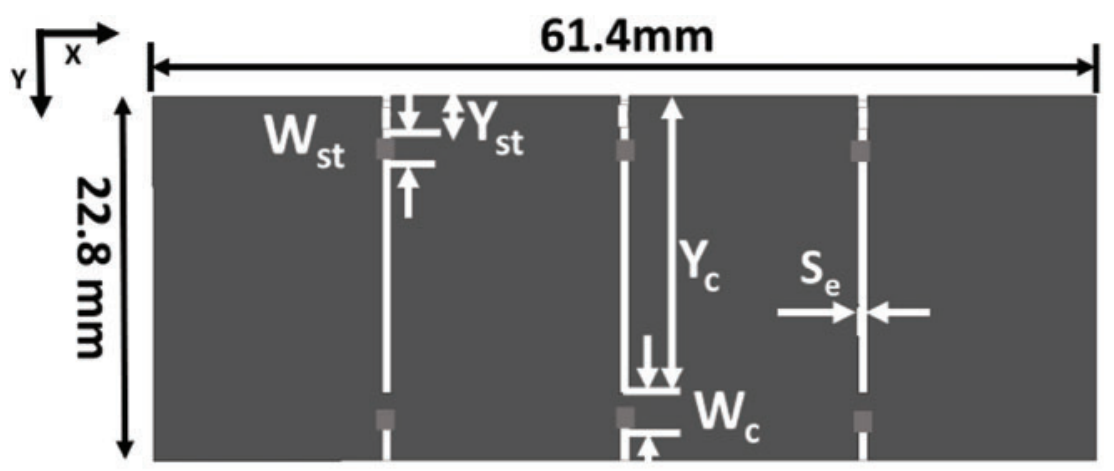

(d)

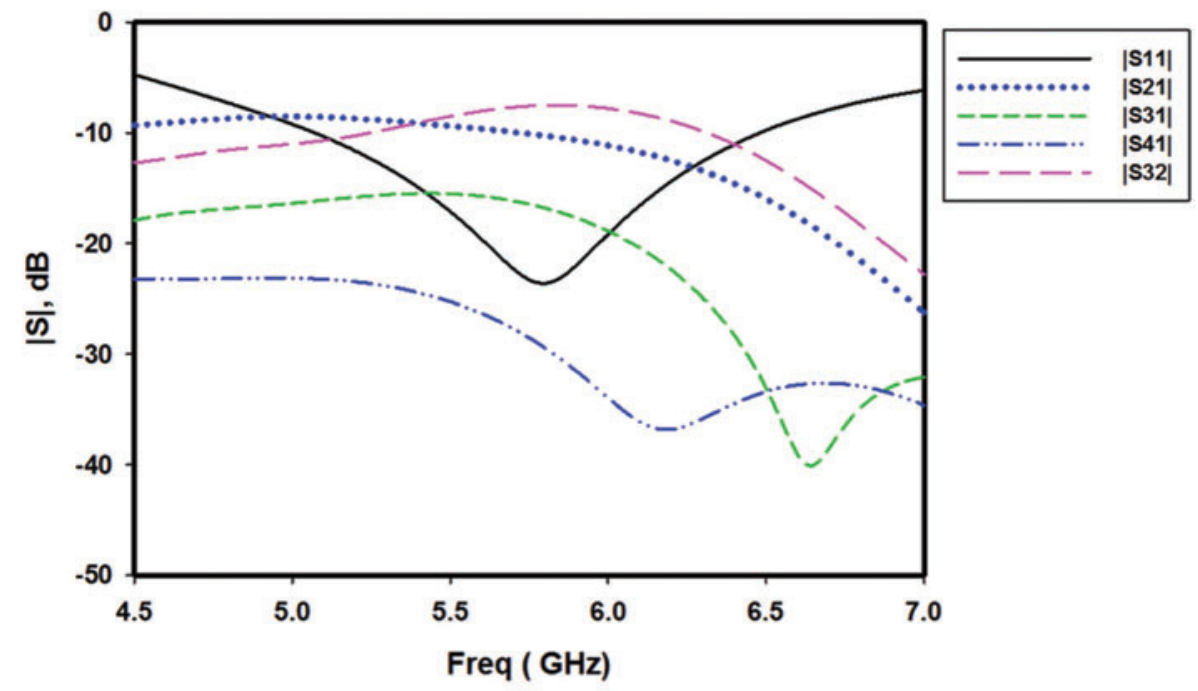

(e)

Figure 8: (a) Single element PIEA (b) S11 and radiation pattern of the PIEA (c\&d) PIEA array top \& Bottom and (e) Array S-parameters

Further, Figs. $8 \mathrm{c}$ and $8 \mathrm{~d}$ shows the configuration of the PIEA array, top and bottom respectively. The array design parameters are given in Tab. 2. The array is designed with $0.3 \lambda o(\lambda o$ at $6 \mathrm{GHz}$ ), spacing by employing mutual coupling reduction techniques. PIEA due to dual shorting pins on the corner forms an inherent slot antenna in-between, which although reduces mutual coupling [25], however, high cross-polarization is observed. Further, three slits, each with a thickness $T_{G}$ are added between top-plate corners of adjacent elements with a separation $S_{G}$ among them, which help to reduce unwanted radiations from naturally formed slot antenna. To reduce the coupling currents, the long slots are introduced in between the adjacent array elements ground plane with a width of Se, and two slits in these slots are introduced at distances $Y_{s \mathrm{t}}$ and $Y_{c}$. Fig. 8e shows the S-parameter results of the array which clarifies, the array exhibits low mutual coupling while maintaining the resonance at $6 \mathrm{GHz}$. 
Table 2: Optimized dimensions of the proposed antenna

\begin{tabular}{llll}
\hline Parameter & Value $(\mathrm{mm})$ & Parameter & Value $(\mathrm{mm})$ \\
\hline $\mathrm{W}=\mathrm{W}_{\mathrm{G}}$ & 14.5 & $\mathrm{Y}_{\text {st }}$ & 0.9 \\
$\mathrm{~L}_{\mathrm{G}}$ & 22.8 & $\mathrm{~W}_{\mathrm{st}}$ & 0.3 \\
$\mathrm{~W}_{\mathrm{S}}$ & 1 & $\mathrm{Y}_{\mathrm{c}}$ & 19.5 \\
$\mathrm{~W}_{\mathrm{f}}$ & 2.17 & $\mathrm{~W}_{\mathrm{c}}$ & 2 \\
$\mathrm{~L}$ & 8.5 & $\mathrm{~d}$ & 15.15 \\
$\mathrm{~h}$ & 2 & $\mathrm{~S}_{\mathrm{e}}$ & 0.65 \\
$\mathrm{~L}_{\mathrm{b}}$ & 4 & $\mathrm{~L}_{\text {slot }}$ & 17.535 \\
$\mathrm{t}$ & 0.5 & $\lambda_{\mathrm{o}}(6 \mathrm{GHz})$ & 50 \\
\hline
\end{tabular}

\section{Multibeam Array Beam Steering Results}

To further test the beam steering capability of the multibeam array, the miniaturized BM is integrated with the PIEA array as shown in Fig. 9. Unlike in the conventional spacing of the array on the BM, in this case, the inter-elements distance between the array is reduced to $0.3 \lambda$ due to the compact nature of the BM. When any port with a $135^{\circ}$ phase shift is excited; it produced a very large back lobe, eventually resulting in the broad beam at zero degrees. In this case, the main beam becomes far away from the zero axis and therefore produces a very strong grating lobe, which overshadowed the main beam and is deposed at the broadside as depicted in Figs. 10 and 11.

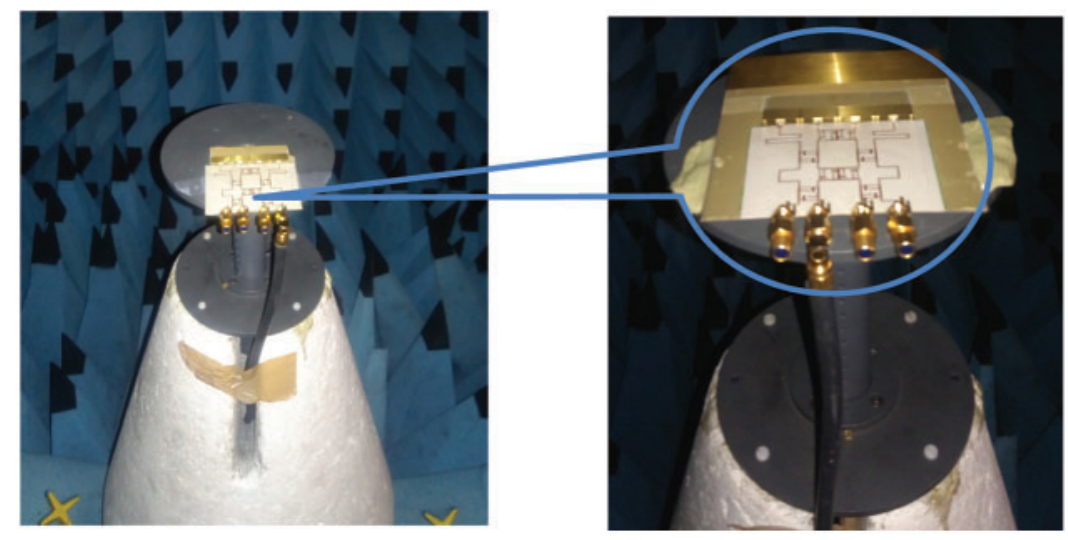

Figure 9: Photograph of the miniaturized Butler matrix with antenna array under test

Even though a BM with broadside beams was presented in [26], the BM has to be modified before realizing the broadside beam. The trick behind obtaining the broadsides beams in this paper was the compactness of the antenna array which eventually resulted in diminishing of the main lobe and enlargement of the back lobes. In this case, the main beam becomes far away from the zero axis and therefore produces a very strong grating lobe, which overshadowed the main beam and is deposed at the broadside. No modification was made from the BM side. However, due to the closeness among the array elements, mutual coupling and cross-polarization reduction techniques were effectively employed. 


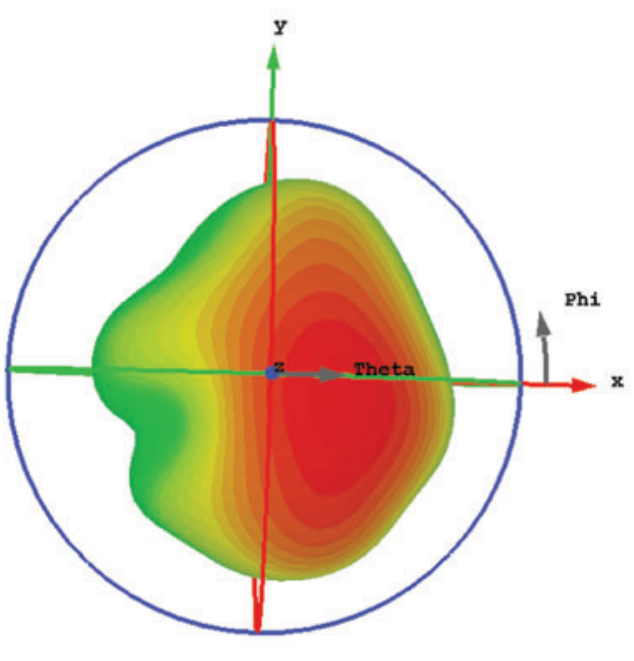

(a)

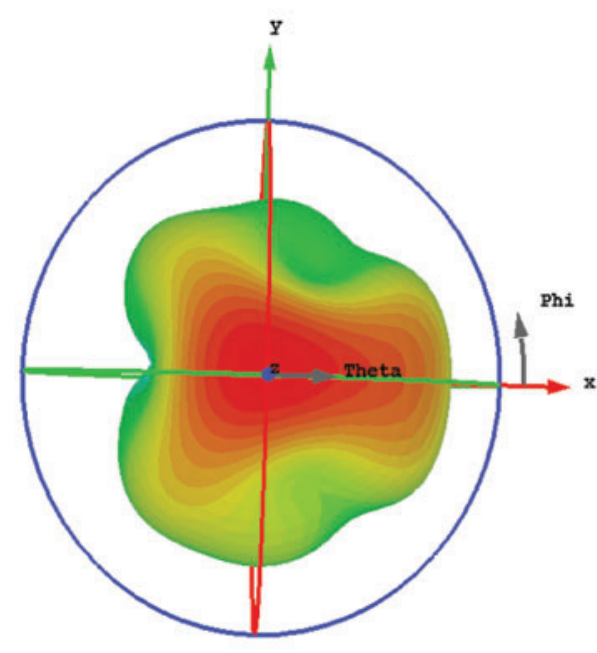

(c)
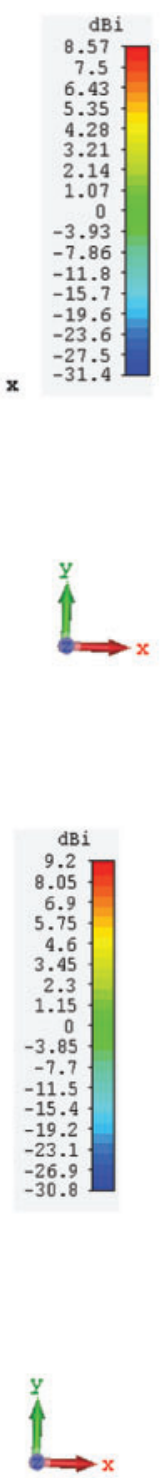

)
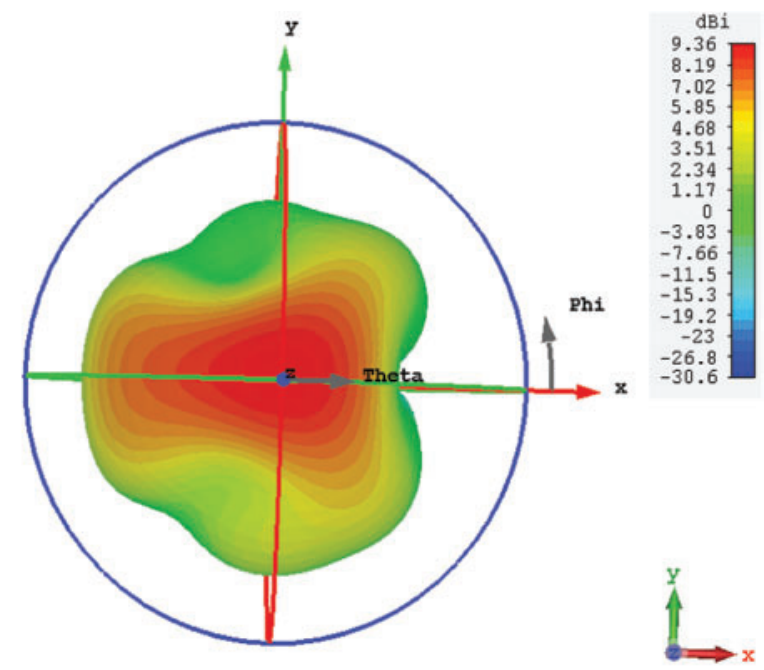

(b)
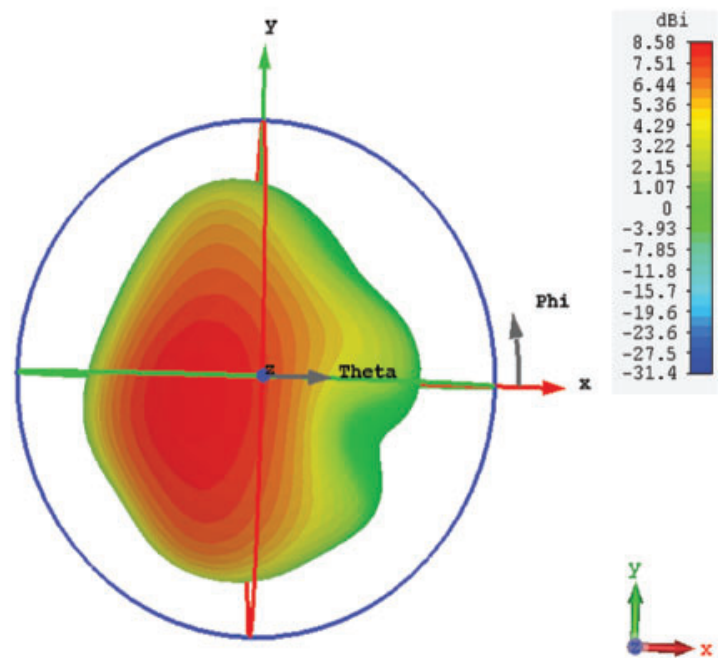

(d)

Figure 10: 3-D Radiation pattern from the compact multibeam array with miniaturized BM (a) Port 1 (b) Port 2 (c) Port 3 and (d) Port 4

The radiation patterns result in three different formats; the 3-dimensional (3-D), polar and cartesian forms are extracted from the simulation software are processed and plotted alongside the measured patterns. The 3D patterns are shown in Fig. 10, while the polar radiation patterns are plotted in Fig. 11. When port 1 is excited with energy, the main beam angle is deposed at $-22.5^{\circ}$ and when port 2 is excited, the main beam angle switched to $0.0^{\circ}$. Similarly, when port 3 and port 4 are excited, the main beams deposed at $+24.35^{\circ}$ and $0.0^{\circ}$ respectively. Hence $0.0^{\circ}$ broadside beam is obtained when either one of the ports among port $2 \&$ port 4 , is excited. 


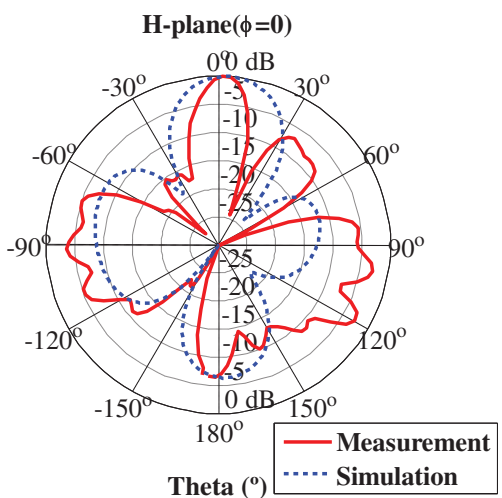

(a)

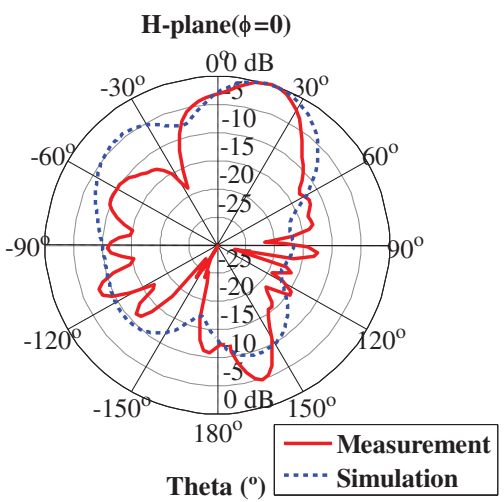

(c)

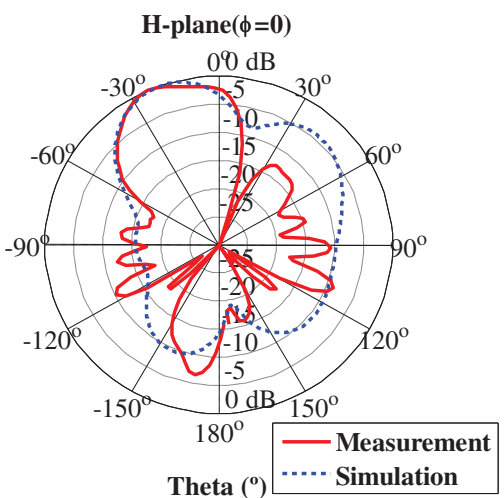

(b)

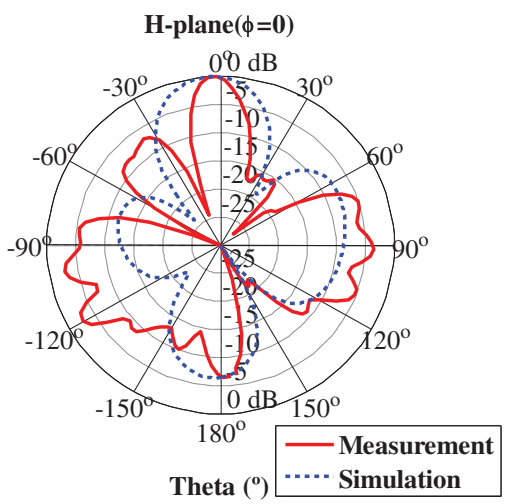

(d)

Figure 11: Radiation pattern from compact multibeam array with miniaturized BM (a) Port 1 (b) Port 2 (c) Port 3 and (d) Port 4

\section{Conclusion}

The standard matrix utilizes $90^{\circ}$ couplers and produces beams symmetrical to the broadside axis which leads to a shadowed area in this direction broadside direction. On the other hand, only the nonstandard matrix usually build from $180^{\circ}$ hybrids produces a broadside beam. However, the structure of $180^{\circ}$ rat-race hybrids and its topology is not suitable for use in the Butler matrix. Also, for the implementation of such type of BM in microstrip technology, the number of crossovers needed will greatly be increased which in turn will complicate the structure of the BM and introduce additional losses due to its complex structure and numerous bent lines at a $90^{\circ}$ angle, especially at higher frequencies. This research succeeded to implement a BM completely build from $90^{\circ}$ in planar microstrip technology that produces a broadside beam. This was achieved by feeding the $\mathrm{BM}$ with an antenna array separated by $0.3 \lambda$. This makes the BM produce the main beam far away from the broadside axis and produces a very strong grating lobe that overshadowed the main beam and is deposed at the broadside. No modification was made from the BM side. However, few effective techniques in the array design were employed that helped to reduce the mutual coupling among the array elements due to their closeness. The validity of this BM was demonstrated by comparing the simulation results of the return losses, transmissions and radiation pattern with 
measurements, the measurement results showed good agreement with simulations. However, apart from little discrepancies between simulations and measured results of the s-parameters from the $4 \times 4$ $\mathrm{BM}$ all other results perfectly agreed.

Acknowledgement: The author acknowledges the research guidance and environment provided by Prof Sharul Kamal Abd. Rahim, Prof. Tharek Abd Rahman, Wireless Communication Centre, Universiti Teknologi Malaysia, and Prof. Mohamed Himdi, Institute of Electronics and Telecommunications of Rennes (IETR), University of Rennes I, France.

Funding Statement: The authors received no specific funding for this study.

Conflicts of Interest: The authors declare that they have no conflicts of interest to report regarding the present study.

\section{References}

[1] J. Butler, "Beam-forming matrix simplifies design of electronically scanned antenna," Electronic Design, vol. 9, pp. 170-173, 1961.

[2] M. Traii, M. Nedil, A. Gharsallah and T. A. Denidni, "Novel UWB multilayer butler matrix," in 2010 IEEE Antennas and Propagation Society Int. Symp., Toronto, ON, Canada, pp. 1-4, 2010.

[3] M. Nedil, M. A. El Cafsi, T. A. Denidni and A. Gharsallah, "Novel UWB CB-CPW butler matrix for wireless applications," in IEEE Antennas and Propagation Society, AP-S Int. Symp. (Digest): Memphis, TN, USA, pp. 1800-1801, 2014.

[4] Y. S. Jeong and T. W. Kim, "Design and analysis of swapped port coupler and its application in a miniaturized butler matrix," IEEE Transactions on Microwave Theory and Techniques, vol. 58, no. 4, pp. 764-770, 2010.

[5] H. Hayashi, D. A. Hitko and C. G. Sodini, "Four-element planar butler matrix using half-wavelength open stubs," IEEE Microwave and Wireless Components Letters, vol. 12, no. 3, pp. 73-75, 2002.

[6] Q. L. Yang, Y. L. Ban, K. Kang, C. Y. D. Sim and G. Wu, "SIW multibeam array for 5G mobile devices," IEEE Access, vol. 4, pp. 2788-2796, 2016.

[7] A. A. M. Ali, N. J. G. Fonseca, F. Coccetti and H. Aubert, "Design and implementation of two-layer compact wideband Butler matrices in SIW technology for Ku-band applications," IEEE Transactions on Antennas and Propagation, vol. 59, no. 2, pp. 503-512, 2010.

[8] S. Aliyubabale, S. H. Lawan, S. K. A. Rahim and S. Ifeomaorakwue, "Implementation of $4 \times 4$ butler matrix using silver-nono instant inkjet printing technology," in 2017 IEEE 3rd Int. Conf. on Electro-Technology for National Development, NIGERCON 2017, Owerri, Nigeria, vol. 2018-January, pp. 514-518, 2018.

[9] T. N. Kaifas and J. N. Sahalos, "On the design of a single-layer wideband butler matrix for switched-beam UMTS system applications," IEEE Antennas and Propagation Magazine, vol. 48, no. 6, pp. 193-204, 2006.

[10] C. W. Wang, T. G. Ma and C. F. Yang, "A new planar artificial transmission line and its applications to a miniaturized Butler matrix," IEEE Transactions on Microwave Theory and Techniques, vol. 55, no. 12, pp. 2792-2801, 2007.

[11] S. C. Gao, L. W. Li, M. S. Leong and T. S. Yeo, "Integrated multibeam dual-polarised planar array," IET Microwaves, Antennas and Propagation, vol. 148, no. 3, pp. 174-178, 2001.

[12] T. K. G. Kwang and P. Gardner, " $4 \times 4$ butler matrix beam forming network using novel reduced size branchline coupler," in 2001 31st European Microwave Conf., London, UK, pp. 1-4, 2001.

[13] E. Gandini, M. Ettorre, R. Sauleau and A. Grbic, "A Lumped-element unit cell for beam-forming networks and its application to a miniaturized Butler matrix," IEEE Transactions on Microwave Theory and Techniques, vol. 61, no. 4, pp. 1477-1487, 2013.

[14] K. Tekkouk, J. Hirokawa, R. Sauleau, M. Ettorre, M. Sano et al., "Dual-layer ridged waveguide slot array fed by a Butler matrix with sidelobe control in the 60-GHz band," IEEE Transactions on Antennas and Propagation, vol. 63, no. 9, pp. 3857-3867, 2015. 
[15] S. A. Babale, S. K. Abdul Rahim, O. A. Barro, M. Himdi and M. Khalily, "Single layered $4 \times 4$ butler matrix without phase-shifters and crossovers," IEEE Access, vol. 6, pp. 77289-77298, 2018.

[16] M. Nedil, T. A. Denidni and L. Talbi, "Novel Butler matrix using CPW multilayer technology," IEEE Transactions on Microwave Theory and Techniques, vol. 54, no. 1, pp. 499-507, 2006.

[17] Y. S. Lin and J. H. Lee, "Miniature butler matrix design using glass-based thin-film integrated passive device technology for $2.5 \mathrm{GHz}$ applications," IEEE Transactions on Microwave Theory and Techniques, vol. 61, no. 7, pp. 2594-2602, 2013.

[18] G. A. Adamidis, I. O. Vardiambasis, M. P. Ioannidou and T. N. Kapetanakis, "Design and implementation of single-layer $4 \times 4$ and $8 \times 8$ butler matrices for multibeam antenna arrays," International Journal of Antennas and Propagation, vol. 2019, pp. 1-12, 2019.

[19] R. Sorrentino and G. Bianchi, "Microwave and RF Engineering," $1^{\text {st }}$ ed., vol. 1. West Sussex, United Kingdon: John Wiley \& Sons, pp. 224-230, 2010.

[20] S. A. Babale and S. K. A. Rahim, "Miniaturized quadrature coupler using low-cost instant inkjet printing technology," Microwave and Optical Technology Letters, vol. 59, no. 8, pp. 1819-1824, 2017.

[21] H. T. Chattha, Y. Huang, M. K. Ishfaq and S. J. Boyes, "Bandwidth enhancement techniques for planar inverted-F antenna," IET Microwaves, Antennas and Propagation, vol. 5, no. 15, pp. 1872-1879, 2011.

[22] M. Kamran Ishfaq, T. Abd Rahman, H. T. Chattha and M. Ur Rehman, "Multiband split-ring resonator based planar inverted-F antenna for 5G applications," International Journal of Antennas and Propagation, vol. 2017, pp. 1-7, 2017.

[23] D. A. Sehrai, F. Muhammad, S. H. Kiani, Z. H. Abbas and M. Tufail, "Gain-enhanced metamaterial-based antenna for 5G communication standards," Computers, Materials \& Continua, vol. 64, no. 3, pp. 1587-1599, 2020.

[24] O. A. Saraereh and A. Ali, "Beamforming performance analysis of millimeter-wave $5 \mathrm{G}$ wireless networks," Computers, Materials \& Continua, vol. 70, no. 3, pp. 5383-5397, 2021.

[25] S. Zhang, S. N. Khan and S. He, "Reducing mutual coupling for an extremely closely-packed tunable dualelement PIFA array through a resonant slot antenna formed in-between," IEEE Transactions on Antennas and Propagation, vol. 58, no. 8, pp. 2771-2776, 2010.

[26] M. Koubeissi, C. Decroze, T. Monediere and B. Jecko, "A new method to design a butler matrix with broadside beam: Application to a multibeam antenna," Microwave and Optical Technology Letters, vol. 59, no. 1, pp. 35-40, 2006. 